WALKER, EA; ROY-BYRNE, PP \& KATON, WJ 1990: Irritable Bowel Syndrome \& Psychiatric lliness. American Journal of Psychiatry, 147: 565 - 571.

WHITEHEAD, WE; BOSMAJIAN, C; ZONDERMAN, AB; COSTA, PT \& SCHUSTER, MM 1988: Symptoms of psychologic distress associated with Irritable Bowel Syndrome: Comparison of Community \& Medical Clinic Samples. Gastroenterology, 95: 709 - 714.

WOLMAN, BB 1988: Psychosomatic Disorders. New York: Plenum.

\title{
REPORT OF VISIT TO HARARE: 27 APRIL TO 15 MAY 1998
}

\author{
Dr Valerie Ehlers, Department of Advanced Nursing Sciences, Unisa.
}

The World Health Organisation (WHO) and the Commonwealth offered a joint workshop for nurses and midwives from the RSA, Mocambique, Zimbabwe, Zambia and Uganda lasting three weeks. Three nurses from the RSA, namely Mrs Mamorwa Gololo from the South African Municipal Workers' Union, Mrs Elza Lubbe from George Hospital and Dr Valerie Ehlers from Unisa, participated in this workshop in Harare.

The primary objective of the workshop was to strengthen the research capabilities of nurses and midwives involved in rendering reproductive health (RH) services. Thus two aspects were addressed throughout the workshop, namely updating the participants' knowledge about $\mathrm{RH}$ issues in the African region and improving their research capabilities, including their statistical capabilities and computer skills, especially the use of the EPI-INFO computer programme.

The workshop's co-ordinators came from Nigeria, Tanzania, the Cameroon and from the WHO's head office in Geneva, Switzerland. Facilitators from the University of Zimbabwe, Harare, included professors from the Department of Obstetrics and Gynaecology, the Department of Public Health, the Department of Epidemiology, and the Department of Sociology.

From Monday till Friday lectures and/or group discussions were conducted from 08:30 until 17:00. During the evenings the representatives from each country were expected to draft their combined research proposal for the country concerned. Two delegates, from two different countries, had to write the minutes of each full day's proceedings. On Saturdays computer practice sessions were provided. Group outings were organised for Sundays.

The three-week workshop concluded with a post-test comparing the delegates knowledge with that displayed during the pretest written at the commencement of the workshop. The organisers were pleased with the progress displayed by the workshop participants. During the last few days each country had to present its research protocol to the whole group for discussion and review. Repeated refinements resulted from these exercises. Each country's delegates left Harare with a proposal for research to be conducted in the country concerned about some aspect of $\mathrm{RH}$.

Subsequent to attending the workshop in Harare, each country's participants were expected to:

- submit a refined research proposal with a detailed budget of expected expenditures within four weeks (this was done by the South African delegation)

- conduct this research and submit a written report within one year (the South African delegation hopes to conduct the actual research early during 1999), and

- share the information obtained in Harare with nurses and midwives from their country. In order to meet this last requirement, a report has been published in Health \& Hygiene ( $\mathrm{vol} 9$, no 10:17-19), emphasising the role which primary health care providers can play in supplying emergency contraceptive services. The information obtained from the planned research will be published widely. Finally, a similar workshop is planned for the nurses and midwives of the RSA, possibly during September 1999.

Much knowledge was gained during the three weeks in Harare, but the greatest benefit involved the co-operation with nursing colleagues from other African countries. All the delegates seemed to experience staff shortages, financial restrictions, inadequate medical supplies and communication problems with health care workers, including doctors, from foreign countries. During the three weeks, the participants became acutely aware of the lack of communication among the nurses from the African continent, as no African Journal for Nurses and Midwives exists. This communication problem is further compounded by the fact that the nurses of Africa do not all understand English - in a number of African countries the official languages are Portuguese or French. The education of nurses in some African countries seems to be modelled on the legacies of the previous colonisers rather than on the health and nursing needs of the specific countries. Nurses and health care planners should address these issues in order to succeed in rendering meaningful nursing care to the people of Africa.

I wish to thank the WHO and the Commonwealth for organising this workshop and for financing it. The Department of Health of the RSA and FUNDISA are thanked for approving my participation in this workshop. Mrs Mamorwa Gololo and Elza Lubbe are thanked for their active participation throughout the workshop and especially for portraying the RH situation in the RSA to the delegates from the other African countries. Finally, my colleagues at the Department of Advanced Nursing Sciences, Unisa, are thanked for enabling me to par* ticipate in this workshop despite their extremely full schedules during 1998.

\section{Reference}

Ehlers, V 1998. Joint World Health Organisation (WHO) and Commonwealth Workshop for Nurses and Midwives: Harare, 27 April to 15 May 1998. Health \& Hygiene, $9(10): 17-19$. 